\section{WITTGENSTEIN: AÇÃO, REGRAS E ASPECTOS}

\author{
WITTGENSTEIN: ACTION, RULES AND ASPECTS
}

\author{
MIRIAN DONAT ${ }^{1}$ \\ (Universidade Estadual de Londrina, Brasil)
}

\begin{abstract}
RESUMO
O artigo trata do problema da ação voluntária a partir das observações de Wittgenstein sobre os conceitos de seguir regras e ver um aspecto. O ponto de partida será a distinção entre comportamento e ação, que deverá mostrar que, diferente dos comportamentos, a ação humana não pode ser reduzida às suas causas, mas tem de ser compreendida em termos das razões que a justificam. O objetivo será mostrar que, em Wittgenstein, esta diferença fundamenta-se na diferença entre o agir de acordo com a regra e o agir seguindo a regra. Além disso, o conceito de ver um aspecto nos ajuda a compreender que a voluntariedade da ação não pode ser reduzida a qualquer tipo de explicação empírica unitária, pois a voluntariedade ou não de uma ação não é algo que possa ser observado e descrito empiricamente, mas é algo que se mostra na ação enquanto aspectos da mesma.
\end{abstract}

Palavras-chave: Ação. Regras. Aspectos.

\begin{abstract}
The article deals with the problem of voluntary action based on Wittgenstein's remarks on the concepts of following rules and seeing aspects. The starting point is the distinction between behavior and action, which should show that unlike the behaviors, human action cannot be reduced to its causes, but must be understood in terms of the reasons for it. The goal will be to show that in Wittgenstein, this difference is based on the difference between acting according to the rules and acting following the rules. Moreover, the concept of seeing an aspect helps us understand the voluntariness of the action cannot be reduced to any kind of unitary empirical explanation for the voluntariness or not of an action is not something that can be observed and described empirically but it is something that is shown in action while aspects of it.

Key words: Action. Rules. Aspects.
\end{abstract}

\section{Introdução}

Pensar as questões que envolvem a ação humana a partir da obra de Wittgenstein deve ter como ponto de partida sua insistência de que estas não são questões que possam ser resolvidas por meio de explicações em termos causais. Wittgenstein rejeita explicações deste tipo, como fica claro já nesta passagem do Livro azul: 


\begin{abstract}
A proposição segundo a qual a sua ação tem uma determinada causa, é uma hipótese. A hipótese terá fundamento se um certo número de experiências forem, falando de uma maneira geral, concordantes, na demonstração de que a sua ação é a consequência habitual de certas condições que, nesse caso, chamamos de causas da ação. Para saber qual a razão para fazerem uma determinada afirmação, para agirem de uma determinada maneira, etc., não é necessário um qualquer número de experiências concordantes, e a exposição de sua razão não é uma hipótese. A diferença entre as gramáticas de 'razão' e 'causa' é bastante semelhante à diferença entre as gramáticas de 'motivo' e 'causa'. (WITTGENSTEIN, 1992, p. 44)
\end{abstract}

Esta passagem nos remete ao parágrafo 90 das Investigações filosóficas, no qual afirma que sua investigação não se refere aos fenômenos, mas sim às "possibilidades dos fenômenos", na medida em que se trata de uma investigação acerca do "modo das asserções que fazemos sobre os fenômenos". Aqui, vemos qual o método que deverá ser adotado para a investigação da questão: uma investigação gramatical dos conceitos, no caso, realizar um esclarecimento do conceito de ação humana, buscando uma "visão panorâmica" do seu uso, que permitirá "ver as conexões" (WITTGENSTEIN, 1996, § 122) deste conceito com outros conceitos, mas também, e principalmente, suas conexões com a totalidade das nossas práticas. Encontramos muitas outras passagens em que trata da questão nos mesmos termos, como por exemplo, na seção XI da segunda parte desta obra onde, ao tratar da experiência de "notar um aspecto" ele afirma ainda que "suas causas interessam aos psicólogos. A nós interessa o conceito e sua posição nos conceitos da experiência".

Este será um elemento fundamental para a correta compreensão do propósito de Wittgenstein, que pretende demonstrar a insuficiência de uma visão cientificista e objetificante da ação humana, que tenta explicar a totalidade da ação humana determinando suas causas imediatas. Esta visão está intrinsecamente relacionada com a concepção de que a linguagem deve ter uma significação uniforme, o que implica não perceber os diferentes aspectos que a linguagem pode revelar, de acordo com os usos que dela são feitos. Neste sentido, a ação humana também revela aspectos que não podem ser abarcados por uma linguagem unitária, que reduz os aspectos da ação a seus aspectos biológicos e fisiológicos, próprios de uma investigação científica.

Obviamente, os avanços e descobertas das ciências relativas ao comportamento humano são inegáveis e não podem ser ignorados em qualquer abordagem que dele se 
faça, no que se inclui a ação consciente e voluntária e levanta vários debates que vão muito além do escopo deste trabalho. Aqui, pretendemos apenas tratar de um ponto específico decorrente destas investidas: a voluntariedade da ação humana. Em geral a questão se coloca em termos da necessidade de se provar por meios empíricos se a ação humana é ou não voluntária, se temos ou não liberdade de escolha, se a liberdade é ou não compatível com a causalidade, sobre o que é a vontade e o querer e assim por diante.

Esta visão cientificista leva à procura de uma resposta unificada para todos os eventos, do mundo e também de nós mesmos em nossa relação com o mundo e com os outros sujeitos. Desta perspectiva, os recentes avanços das ciências cognitivas e das neurociências, por exemplo, pretende utilizar os mesmos conceitos e métodos das ciências físicas para desenvolver uma explicação do comportamento humano, que leve a uma explicação definitiva, totalizante e unitária. Para isto, esta explicação deve considerar o comportamento naquilo que pode se observado, quantificado, objetivado, ou seja, determinados processos físico-químicos que têm lugar no cérebro, no sistema nervoso ou nos neurônios, por exemplo, que serão então considerados as causas explicativas do comportamento humano.

Em si mesma, uma investigação causal do comportamento humano, como essa, não é problemática, pois como disse o próprio Wittgenstein, está-se aí no nível das causas e este é propriamente o objeto da ciência. O problema aparece quando se extrapola este nível e se tenta encontrar "respostas" causais para questões que estão além dele. Esta situação é gerada pela falta de clareza dos próprios conceitos envolvidos nas questões e, principalmente, a falta de clareza da origem e lugar próprios destes conceitos.

Não vamos considerar e analisar as diferentes formulações e explicações para o problema, pois nosso foco não será a crítica ou a refutação de alguma ou algumas destas propostas, mas sim em mostrar que a própria pergunta está mal formulada, e que o principal equívoco reside na crença de que todas as questões que se podem colocar acerca da ação humana devem ser reduzidas a questões que a ciência deva responder. Pretendemos mostrar, a partir de Wittgenstein, que nem a pergunta nem os conceitos envolvidos nestas questões são empíricos, o que nos leva a investigar qual é a origem, significado e lugar destes conceitos, ou seja, pretendemos alcançar uma visão 
panorâmica destes conceitos, cuja falta é a fonte principal de nossa incompreensãoda questão.

\section{Comportamento e ação}

As ações humanas podem ser consideradas de uma dupla perspectiva, aquilo que chamaremos comportamentos e ação propriamente dita. Em relação ao comportamento, estes podem ser investigados de um ponto de vista puramente empírico, o que significa tomar o ser humano em seus aspectos biológicos tão somente e considerar então o seu comportamento em termos físicos, determinando as suas causas. No nível do comportamento, investigam-se as atividades de um corpo em termos de observação, quantificação e generalização do que nele acontece. Aqui as explicações serão realizadas a partir de um sistema conceitual descritivo que se organiza em hipóteses a serem comprovadas pela experiência. $\mathrm{O}$ sistema conceitual que permite a pesquisa neste nível envolve conceitos tais como causa, efeito, movimento, hipótese. O ponto fundamental aqui é que estas explicações acontecem como que de fora, no sentido de que se investiga algo que acontece com o sujeito, mas não algo que efetivamente é feito por ele.

Entretanto, nem todos os aspectos da ação humana podem - nem devem - ser explicados neste nível causal. Entre as atividades humanas existem aquelas que precisam de um tipo de explicação que demanda uma justificativa para o que se faz. E aqui encontramos uma diferença entre aquilo que podemos chamar de comportamento e a ação propriamente dita. Esta diferença reside em dois elementos fundamentais da ação especificamente humana; por um lado a existência de um sujeito da ação, sujeito que será aquele a quem se atribui a origem da ação e a quem se demandam as justificativas para o modo como age e, por outro lado, o reconhecimento de que estas ações são intencionais, no sentido de que são dirigidas para determinado objeto, elas têm um propósito. As duas características se complementam e juntas mostram a diferença essencial entre comportamento e ação.

Dizer que as ações são próprias de um sujeito e intencionais implica em considerá-las para além dos puros comportamentos de acordo com o significado que possuem e cujas razões devem ser dadas pelo sujeito da ação. A questão que se coloca é justamente como explicar o significado da ação humana, como se estabelece este significado. Em outras palavras, quando é de ação que se trata, a pergunta que se coloca 
é sobre o que explica a própria intencionalidade, ou, ainda, sobre quais são os fundamentos que temos para agir da maneira como agimos.

E a resposta é que as razões são justamente aquilo que dá à ação o seu significado, na medida em que é a razão que serve como explicação do modo como o sujeito age. Um movimento ou comportamento humano pode ser descrito e explicado determinando-se suas causas fisiológicas ou neurofisiológicas, mas o significado deste movimento não. É aqui que acontece a passagem de um simples comportamento para a ação propriamente dita, um movimento torna-se gesto significativo, expressivo. $\mathrm{O}$ ato de levantar o braço tem suas causas, dependem de uma condição fisiológica e neurofisiológica, mas para que seja um gesto de aceno, um pedido de ajuda ou um alerta este ato precisa ir além dessas explicações e conectar-se com as razões e motivos que o sujeito tem ao mover o braço da forma que move. Quando se trata de ação humana é preciso voltar-se para a compreensão do sentido desta ação, uma vez que a ação humana, para além de uma atividade mecânica, é uma ação de um sujeito, por isso, intencional e significativa; a intencionalidade da ação é o que empresta a ela seu significado. Um comportamento não tem significado nestes termos, ele pode ser descrito por suas características observáveis, que não se alteram de sujeito para sujeito, elas serão sempre as mesmas, podendo ser generalizadas.

Vê-se assim que os comportamentos podem ser explicados conclusivamente e suas causas podem mesmo não ser conhecidas pelo sujeito que realiza os movimentos correspondentes, há uma independência entre a causa e o efeito, o que significa que se pode descrever um comportamento sem saber qual é a sua causa e o sujeito pode agir sem o conhecimento da causa. A razão nunca pode ser desconhecida do sujeito, pois é justamente dele de quem exigimos que apresente as razões para a sua ação e ela será, nesse sentido, necessariamente a explicação da ação, ela explica porque o sujeito age da forma como age. Obviamente, os outros sujeitos podem avaliar a adequação ou não, a correção ou não, destas razões. Isso mesmo prova que as razões pertencem a um âmbito diferente das explicações causais, pois dependem sempre de um contexto intersubjetivamente compartilhado no qual se estabelecem as razões para a ação, contexto do qual faz parte, ativamente, o sujeito da ação.

Dizer que a voluntariedade da ação se encontra no plano da intencionalidade significa dizer que é o sujeito quem dá origem a esta ação, na medida em que a conecta com seus objetivos e propósitos, por isto esta ação é realizada de uma determinada 
maneira, que poderia ter sido outra. Se dependesse de um ato da vontade ou qualquer coisa do gênero, não poderia ter tal característica; nesse caso seria algo que simplesmente acontece ao sujeito e então não teria maneiras de acontecer: uma experiência é o que é, não pode ser de outro modo. Se assim o fosse, seria algo que simplesmente nos acontece, não algo que realmente fazemos porque queremos fazer. Wittgenstein nega a separação entre a vontade ou o querer e a própria ação voluntária. Se houvesse algo como "a vontade" ou " o querer" que pudesse ser investigado, descrito e demonstrado como a causa da ação, então a própria ação não poderia mais ser compreendida como voluntária, pois esta seria simplesmente causada por atos da vontade ou seriam derivações do querer, o que anularia a voluntariedade.

Por isso, para compreender a ação humana tendo em vista a voluntariedade desta ação precisamos considerá-la a partir de conceitos diferentes daqueles das ciências; neste âmbito é que aparecem conceitos tais como motivo, razão, vontade, querer. Desta perspectiva as ações voluntárias terão uma conexão direta com o contexto sóciohistórico-cultural, pois elas só podem ser compreendidas em relação a este contexto, na medida em que é nele que se constitui a rede conceitual de acordo com a qual julgamos uma ação. Desta maneira, as razões devem ser buscadas de um modo diferente daquele da observação do comportamento, pois requer, para sua compreensão, uma investigação profunda das instituições próprias de uma determinada forma de vida. Quando de ação se trata tem de se considerar o ser humano em uma forma mais ampla, não apenas naqueles aspectos que podem ser observados diretamente no comportamento.

No parágrafo 107 das Investigações Wittgenstein escreve:

Quanto mais exatamente consideramos a linguagem de fato, tanto maior torna-se o conflito entre ela e as nossas exigências. (A pureza cristalina da lógica não se entregou a mim, mas foi uma exigência.) $\mathrm{O}$ conflito torna-se insuportável; a exigência ameaça tornar-se algo vazio. - Caímos numa superfície escorregadia onde falta o atrito, onde as condições são, em certo sentido, ideais, mas onde por esta mesma razão não podemos mais caminhar; necessitamos então o atrito. Retornemos ao solo áspero!

Esta passagem mostra, de outra perspectiva, o que está aqui sendo proposto. $\mathrm{O}$ filósofo, ou o cientista, que tenta explicar o comportamento puramente a partir de suas 
causas encontra-se na situação daquele que tenta explicar a linguagem retirando-a de seu solo de origem. Lá onde a linguagem encontra a pureza cristalina da lógica, não é mais da nossa linguagem que se trata, da mesma maneira que tentar explicar desta forma o comportamento humano retira dele toda a significação que possui, restando, digamos, a pureza cristalina do comportamento, que não mais reconhecemos como sendo o nosso "modo comum de agir".

\section{Ação voluntária e regras}

Em Wittgenstein a diferença entre comportamento e ação está ligada com sua explicação sobre a diferença entre seguir a regra e apenas agir de acordo com a regra. $\mathrm{Na}$ passagem que trata do seguimento de regras, nas Investigações Filosóficas, Wittgenstein demonstra que, diferente do simples agir de acordo com a regra, seguir a regra depende de que o sujeito efetivamente tenha a regra em consideração como sendo a razão para sua ação: “ccomo posso seguir uma regra?’ - se isto não é uma pergunta pelas causas, é então uma pergunta pela justificação para o fato de que eu ajo segunda a regra assim”(WITTGENSTEIN,1996, § 217). Como seres usuários da linguagem ultrapassamos o nível causal do comportamento e conectarmos nossa ação com as regras intersubjetivamente compartilhadas de uma forma de vida: "uma diferença entre condicionalidade causal e condicionalidade lógica" (WITTGENSTEIN, 1996, § 220). Por isso, neste plano não faz sentido buscar explicações das ações humanas de acordo com alguma regularidade natural simplesmente, mas sim buscar as razões das ações, o que significa tentar compreender as regras de acordo com as quais estabelecemos aquilo que é correto ou não, que devemos ou não fazer.

E o fundamento da regra é o contexto efetivo de uso da regra, não há um além deste contexto que possa justificar a regra. É o contexto dentro do qual o sujeito age e dentro do qual aprende o que deve e o que não deve fazer, ele escolhe como agir com referência a conceitos, contextualmente definidos, do que está ou não de acordo com a regra, que conecta o agente a um modo de agir comum daquela forma de vida. As regras guiam a ação do sujeito no sentido de serem as razões, referidas ao contexto que o sujeito oferece em favor de sua ação. A intencionalidade e voluntariedade da ação estão conectadas com o seguimento de regras, pois para que se possa ter a intenção de realizar uma ação, esta deve já estar dada num contexto regrado que conforma e normatiza aquela ação. Neste sentido que, segundo Wittgenstein, pode-se dizer que se assemelha 
ao jogo. Um movimento dentro de um jogo torna-se significativo e efetivamente um lance dentro daquele jogo se existe uma regra que determine que aquele é um lance dentro deste jogo, ou, de maneira mais ampla, se existe algo como jogar aquele jogo: só posso jogar xadrez e ter a intenção de jogar xadrez se em minha forma de vida existe a prática de jogar xadrez: "a intenção está inserida na situação, nos hábitos humanos e nas suas instituições. Se não existisse a técnica de jogar xadrez, eu não poderia ter a intenção de jogar uma partida de xadrez" (WITTGENSTEIN, 1996, § 337). Da mesma maneira, dizer que uma ação é voluntária depende da consideração do contexto em que se realiza esta ação, pois é lá onde se constitui isto o que chamamos ação voluntária. Não existe algo em si que possa ser considerado a vontade ou o querer, do qual deveriam derivar as ações voluntárias, independente deste conceito dado no contexto de uma forma de vida. A partir deste momento pode-se responsabilizar o sujeito pela ação, e é isto o que significa que ele efetivamente escolhe agir tendo como justificação uma razão específica e não outra. Se não houvesse uma situação comum a qual chamamos ação voluntária então não faria nenhum sentido avaliar determinados comportamentos específicos como sendo involuntários. Eles assim serão considerados justamente porque fogem do padrão estabelecido.

Assim, a explicação da ação voluntária não pode ser buscada no indivíduo isolado, em seus atos, estados e processos mentais, mas no "ser humano vivo" que compartilha com outros sujeitos uma forma de vida na qual, conjuntamente, constituem os valores que dão sentido às suas ações. Diante destes valores o sujeito faz a sua escolha, coordenando suas ações às regras que estabelecem o que se deve ou não fazer, o que é bom e o que não é, o correto e o incorreto. Desta perspectiva ele pode ser avaliado pelos outros sujeitos com quem interage, agora sua ação pode ser considerada correta ou não, adequada ou não, boa ou má. Ele pode, portanto, ser responsabilizado pela ação, pode ser julgado, condenado e punido.

Ele pode agir em puro acordo com alguma regra, como acontece no nível do comportamento mecânico, mas ele pode também agir no sentido de seguir a regra; neste segundo caso ele torna-se sujeito da ação, na medida em que a regra torna-se a justificativa, portanto, razão para a ação. Essa diferença mostra quando é que se pode imputar ao sujeito a responsabilidade por sua ação. Se ele apenas realiza uma ação de acordo com a regra, movido por qualquer causa externa, não pode ser responsabilizado. 
Mas quando a razão de sua ação é a regra que deliberadamente segue então sua ação é voluntária e pode ser cobrado por ela.

Se não houvesse essa distinção entre comportamento e ação, entre agir de acordo com a regra e seguir a regra, não haveria também a possibilidade de responsabilizar o sujeito pelo que faz. Se tudo pode ser explicado em termos físicos, então o sujeito efetivamente não $f a z$ alguma coisa, mas sim algo lhe acontece devido a uma determinada configuração físico-química de seu corpo, sem que o sujeito pudesse ser responsabilizado por isso.

Aqui chegamos a um ponto fundamental. Quando tratamos de conceitos tais como a liberdade, o querer e a vontade temos que pensar na descrição do sentido da ação humana e isto não pode ser feito deslocando-se esta prática, ou, talvez pior, recortando esta prática em segmentos. A prática humana significativa tem de ser compreendida a partir de um pano de fundo ele também significativo. A compreensão da ação humana não acontece a partir da explicação de aspectos isolados desta prática, mas sim de acordo com este pano de fundo regrado, que é o horizonte último de compreensão da ação. O que significa propriamente 'humano' tem de ser buscado neste fundo comum das práticas humanas, que tem seu significado estabelecido de acordo com as práticas discursivas, portanto, é de um horizonte linguístico de que se trata. $\mathrm{O}$ significado da ação será alcançado de acordo com os conceitos determinantes desta prática compartilhada pelos sujeitos de uma forma de vida, que instituem seus jogos de linguagem a partir de valores comuns, intersubjetivamente instituídos e compartilhados. Este sentido tem de ser compreendido de acordo com a pragmática das nossas formas de vida. E isto significa levar a sério a recomendação de que o significado da ação humana não pode ser deslocado do espaço próprio de realização das mesmas: as ações humanas acontecem no fundo comum das formas de vida, que reúne 'hábitos, costumes, instituições' que se conectam numa rede conceitual de acordo com a qual se estabelece o significado da ação.

Há contextos de uso nos quais são determinados os significados dos conceitos de vontade, querer, intenção e é neles que se deve buscar sua significação. Há um jogo de linguagem que é o jogo da linguagem da vontade e da intenção. O esclarecimento deste jogo de linguagem deverá mostrar que o problema com a vontade e com a intenção é um problema gramatical, não empírico nem transcendental. O critério de significado destes 
conceitos, como, aliás, de qualquer outro, é determinado pelo contexto de uso, ele é normativo das práticas mesmas que dizemos voluntárias ou intencionais.

Uma atitude científica diante da ação humana faz com que ela torne-se um fato entre outros fatos quaisquer, que tem uma explicação por meio das causas e seus efeitos. Mas os conceitos que envolvem a pergunta pela ação voluntária ultrapassam este nível, e não faria sentido buscar a "causa" de uma ação voluntária ou uma "prova" de que uma ação voluntária não existe. Vontade, liberdade, querer estão num plano distinto do plano da ciência, e desde o Tractatus encontramos Wittgenstein insistindo em que a tentativa de dar a eles uma explicação científica retiraria deles seu sentido. A ciência só pode tratar de fatos e suas causas, mas os valores de acordo com os quais avaliamos uma ação não estão neste plano. Se estivessem deixariam de ser valores (por mais paradoxal que possa parecer esta afirmação).

\section{Ação voluntária e aspectos}

Da perspectiva de Wittgenstein, vemos que são duas formas de descrever e explicar a ação humana, cada uma com suas próprias especificidades. Não considerar esta diferença leva a tentar compatibilizar dois jogos de linguagem distintos, o que não tem sentido, pois cada jogo de linguagem diz respeito a aspectos distintos da ação humana, envolvem modos de descrição desta ação que não tem de ser compatibilizadas. É levar para dentro do jogo de linguagem no qual lidamos com as ações voluntárias os conceitos próprios da linguagem causal e mecanicista da descrição física dos eventos naturais, próprio da ciência.

O conceito de "ver um aspecto" pode ajudar a esclarecer o modo como Wittgenstein entende o problema da ação voluntária em sua fase madura. Apesar de não fazer explicitamente esta relação, podemos depreender de suas observações sobre o ver aspectos, na seção XI da segunda parte das Investigações Filosóficas, elementos importantes para a compreensão do conceito de ação voluntária.

$\mathrm{Na}$ passagem citada a questão fundamental que se coloca para Wittgenstein diz respeito à diferença conceitual entre o simples ver e o ver um aspecto em figuras. $\mathrm{O}$ ponto fundamental desta distinção, que aqui nos interessa, diz respeito ao fato de que o ver um aspecto não pode ser objetivamente descrito, tal como o pode o ver. O exemplo de Wittgenstein é aquele de alguém que vê uma figura e para quem se pede que descreva o que vê; a descrição se dará em termos da descrição das propriedades e 
qualidades da figura, que podem ser observadas por qualquer um que se volte para a mesma figura. $\mathrm{O}$ caso do ver um aspecto é completamente diferente, pois o aspecto não é uma propriedade ou qualidade do objeto, ele não pode ser observado desta forma nem pode ser descrito nestes termos. No ver o aspecto o importante é ver a figura como figura de algo. Há aqui uma relação interna entre a figura e aquilo de que é figura que só pode ser compreendida por alguém que teve já uma certa vivência, algo como a vivência do aspecto. Só este é quem pode, por exemplo, reconhecer a figura pato-lebre ora como pato ora como lebre ou ainda a semelhança que existe entre dois rostos. Este último caso nos mostra claramente como o aspecto não pode ser percebido no objeto, pois por mais que façamos descrições de um rosto e de outro, não conseguimos descrever a "semelhança", pois esta não é uma propriedade que possamos perceber: "o ver como não pertence à percepção. E por isso é como um ver e também não é como um ver" (WITTGENSTEIN, 1996, p. 180).

Como afirmamos, nesta passagem Wittgenstein não relaciona o conceito de ver um aspecto com a ação voluntária propriamente, ou com a ação humana de qualquer maneira. Além de ver aspectos em figuras ele relaciona este conceito com o conceito de vivência da significação de uma palavra e também apresenta algumas observações que dizem respeito ao modo como podemos reconhecer as expressões uns dos outros. Esta última relação pode ser vista em passagens como a seguinte: "Alguém que vê um sorriso que não reconhece como sorriso, não o compreende, não o vê de modo diferente daquele que o compreende? - Ele o imitaria de modo diferente, por exemplo" (WITTGENSTEIN, 1996, p. 181) ou: "como podia ver, pois, que essa atitude era tímida, antes de saber que é uma atitude e não a anatomia deste ser?" (WITTGENSTEIN, 1996, p. 190)

Para compreender adequadamente esta distinção entre ver e ver um aspecto é preciso ter em mente a profunda consideração que Wittgenstein tinha pela capacidade expressiva da linguagem. Esta capacidade aparece já nas considerações sobre o argumento da linguagem privada, em que demonstra que a principal questão por detrás da discussão sobre a possibilidade de uma linguagem privada é a desconsideração de uma característica fundamental da linguagem psicológica, que é justamente que esta linguagem, ao menos em alguns de seus usos, não tem como objetivo descrever o que se passa com o sujeito, mas sim expressar aquilo que consideramos, nesse jogo de linguagem, "interno" ao sujeito. 
Esta capacidade expressiva da linguagem está diretamente relacionada às observações sobre o ver um aspecto, em seus múltiplos sentidos, pois para ver o aspecto de uma figura, para compreender a significação de uma palavra ou para reconhecer a expressão de um rosto, é fundamental que se tenha uma determinada vivência, vivência esta que acontece no fundo comum de uma forma de vida, dentro da qual se estabelecem, por meio de nossas práticas cotidianas, permeada de sentimentos, afetos e experiências, os valores comuns que serão determinantes de nossas ações.

Em relação à ação humana voluntária, estas observações sobre o ver aspectos, levam a perceber duas linhas de aproximação entre os conceitos. A primeira aproximação pode ser compreendida como um não reducionismo no que diz respeito às análises acerca da ação humana voluntária e isto significa compreender que uma investigação puramente científica ou empírica acerca da ação voluntária não dá conta de explicar os diferentes aspectos da mesma. Obviamente, para que um sujeito possa realizar uma ação voluntária determinados movimentos e comportamentos são necessários, mas a intencionalidade e a voluntariedade não podem ser reduzidas a aspectos empíricos destes movimentos e comportamentos. Há elementos que só podem ser compreendidos em uma visão mais ampla que inclua as razões, e não apenas as causas, para a realização da ação.

Neste sentido, as razões podem ser compreendidas como aspectos da ação, uma vez que, da mesma maneira que os diferentes aspectos de uma figura não se prestam a uma observação perceptual direta, as razões não são observáveis, seja enquanto causas para uma ação seja enquanto qualquer coisa que vá pela mente do indivíduo, tal como o ato da vontade compreendido enquanto um ato mental anterior à efetiva realização da ação.

Portanto, a ação humana deve ser compreendida de um modo não reducionista, o que significa que a ciência não é a única nem a última palavra no que diz respeito à explicação da ação humana. A ciência explica aspectos deste comportamento, mas outros aspectos devem ser considerados se queremos ter uma compreensão adequada. Seguindo algumas considerações acerca do conceito de ver um aspecto, podemos agora entender que a ação humana voluntária revela aspectos desta ação.

Aqui encontramos a segunda linha de aproximação entre os conceitos de ação voluntária e ver aspectos, na medida em que podemos entender conceitos tais como consciência, vontade, querer, liberdade como aspectos da ação humana, que se revelam 
em um comportamento expressivo. A distinção fundamental entre uma linguagem descritiva e uma linguagem expressiva revela a busca de Wittgenstein por uma explicação da ação humana que não se reduzisse aos parcos meios da ciência, que é incapaz de reconhecer os aspectos expressivos da ação e da linguagem humana. Neste sentido, o reducionismo cientificista pode ser comparado à "cegueira para o aspecto". O cego para o aspecto não é capaz de perceber os diferentes aspectos que se revelam em uma figura, ou os diferentes aspectos que uma palavra pode adquirir, ele não tem a vivência da significação, por isso está impossibilitado de perceber os diferentes aspectos que se revelam nas figuras e nas palavras.

Da mesma maneira, as ações humanas revelam diferentes aspectos que, conjuntamente, nos permitem a compreensão do especificamente humano nestas ações. O cientista com suas atitude e linguagem objetificantes, retira da ação exatamente sua expressividade, restando apenas o comportamento na sua frieza e falta de significado. Os aspectos efetivamente "valiosos" da ação são descartados. A ciência descreve o comportamento num sentido puramente mecânico, estático, não pode - nem deve - dar conta dos aspectos expressivos da ação propriamente dita. A expressividade da ação humana não é algo que possa ser observado no comportamento, não é uma característica que possa ser alcançada desta forma, da mesma maneira que os aspectos que se revelam em uma figura não podem ser observados, não percebemos diretamente um aspecto na própria figura, o aspecto é uma relação interna entre um objeto e outros objetos.

Se colocarmos novamente a pergunta pelos fundamentos da ação voluntária considerando o conceito de ver um aspecto, ou, dito de outro modo, a pergunta pelos fundamentos das razões que temos para agir da maneira que agimos, teremos em primeiro lugar que considerar que a intencionalidade está relacionada com as atividades conscientes de um sujeito, ela liga a ação a motivos e razões. Entretanto, a intencionalidade não pode ser observada diretamente no comportamento, ela é expressa pelo sujeito da ação, na forma de motivos e razões para fazer o que faz e para fazer do modo que faz. Este modo de expressão da intencionalidade é a linguagem, pois é na apresentação dos motivos e razões que se "vê" a intencionalidade da ação. Se não existe algo que seja observável no comportamento que nos permita determinar se uma ação é ou não voluntária, isto deverá ser feito de acordo com uma rede conceitual que nos oferece uma perspectiva de acordo com a qual podemos então julgar se é ou não voluntária. 
Além disso, seguindo as observações sobre ver um aspecto encontramos outro elemento que é torna fundamental para Wittgenstein: quando se trata da ação humana propriamente dita o que realmente importa é o modo como agimos uns em relação aos outros e ao mundo. Isto significa que no nível da ação humana esperamos muito mais do que uma explicação das causas desta ação. Aquele que age tendo como justificativa razões e não causas tem uma atitude diferente diante do mundo e da vida, ele age em relação aos outros esperando que os mesmos também tenham com ele uma reação de um tipo adequado. Esta atitude perante o mundo, a vida e os outros sujeitos é o ponto fundamental das preocupações de Wittgenstein, e mostram, creio eu, que sua interrogação sobre a ação humana não teve respostas tão distantes assim em seus últimos escritos em relação aos primeiros. Há algo que empresta valor as nossas ações e esse algo não pode ser descrito e explicado por uma investigação científica, ela não pode ser reduzida as explicações mecânicas e objetivantes da ciência.

Tentativas inúteis e desnecessárias de tentar encontrar o "algo em comum", esse algo que possa explicar definitivamente o especificamente humano, é aquela ânsia de generalização que não cessa de nos atormentar, e que nos impele sempre em busca de explicações exatas e definitivas, resultado de um desejo profundo de sair do "solo áspero" e encontrar explicações que nos confortem, pois estas trazem ordem ao caos cotidiano. Entretanto, a tarefa da filosofia é justamente fazer cessar essa procura, a paz tanto almejada só será alcançada quando se tiver compreendido que esta encontra-se justamente no horizonte comum da ação humana, a sua forma de vida, com sua linguagem, suas práticas, suas instituições, fundo comum e fundamento de tudo aquilo que se diz "humano". 


\section{Nota}

1 Professora do Departamento de Filosofia e do Programa de Pós-Graduação em Filosofia da Universidade Estadual de Londrina (UEL), Londrina, P.R, Brasil. e-mail: donat@uel.br 


\section{Referências}

CAVELL, Stanley. The claim of reason. New York; Oxford. Oxford University Press, 1979.

DAY, William \& KREBS, Victor J. Seeing Wittgenstein anew. New York: Cambridge University Press, 2010.

HACKER, P. M. S. Natureza humana: categorias fundamentais. Porto Alegre: Artmed, 2010.

MARQUES, A. O interior: linguagem e mente em Wittgenstein. São Paulo: Edições Loyola, 2012.

MULHALL, Stephen. Seeing aspects. In: GLOCK, Hans-Johann. Wittgenstein: a critical reader. Oxford: Blackwell, 2001.

WITTGENSTEIN, L. Investigações Filosóficas. Segunda Edição. Trad. de José Carlos Bruni. São Paulo: Abril Cultural, 1979.

WITTGENSTEIN, L. O livro azul. Lisboa: Edições 70, 1992.

WITTGENSTEIN, L. Observações sobre a filosofia da psicologia. Vol. I e II. Trad. de Ricardo H. P. Machado. Aparecida, SP: 2008.

WITTGENSTEIN, L. Últimos escritos sobre a filosofia da psicologia. Trad. de Antonio Marques, Nuno Venturinha e João Tiago Proença. Lisboa: Calouste Gulbenkian, 2007. 